\title{
Comprehensive determination of the solid state stability of bethanechol chloride active pharmaceutical ingredient using combined analytical tools
}

\author{
Romain Rotival, $t^{* a b}$ Yohann Corvis, ${ }^{a}$ Yohann Cartigny, ${ }^{c}$ Philippe Négrier, \\ Mathieu Marchivie, ${ }^{f}$ Stéphane Massip, ${ }^{f}$ Inès Gana, ${ }^{\mathrm{b}}$ Pascale Lemoine ${ }^{\mathrm{g}}$ \\ and Philippe Espeau ${ }^{a}$
}

\begin{abstract}
The use of an integrative analytical approach allowed us to establish the intrinsic solid state stability of bethanechol chloride (BC), an active pharmaceutical ingredient used in the treatment of urinary retention. First, the crystal structure of the monoclinic form has been described using single crystal $X$ ray diffraction studies. Second, thermal analyses revealed that the compound degrades upon melting, with an apparent melting temperature estimated to be $231{ }^{\circ} \mathrm{C}$. No transition from the monoclinic to the orthorhombic form has been observed, suggesting that the monoclinic form is the stable one. Third, the two step melting decomposition process has been elucidated by liquid chromatography and thermogravimetry coupled to mass spectrometry. The first step corresponds to the sample liquefaction, which consists of the gradual dissolution of bethanechol chloride in its liquid degradant, i.e. betamethylcholine chloride. This step is in agreement with Bawn kinetics and the activation energy of the reaction has been estimated at $35.5 \mathrm{kcal}$ mol ${ }^{1}$. The second step occurs with accelerated degradation in the melt. Elucidation of secondary decomposition pathways evidenced autocatalytic properties conferred by the formation of both isocyanic acid and methyl chloride. Finally, dynamic water vapor sorption analysis showed a substantial hygroscopicity of the drug substance. A deliquescent point has been determined at $56 \%$ relative humidity at $25^{\circ} \mathrm{C}$.
\end{abstract}

\section{Introduction}

Bethanechol chloride (BC), otherwise known as 2-carbamoyloxypropyl(trimethyl)azanium chloride, is the $\beta$-methyl choline carbamoyl salt. The pharmacological effect of BC occurs primarily on postganglionic parasympathetic receptors. The contractive effect on the urinary bladder makes this drug

${ }^{a}$ Laboratoire Physico Chimie Industrielle du Médicament, EA 4066, Université Paris Descartes, Sorbonne Paris Cité, Faculté des Sciences Pharmaceutiques et Biologiques, 75006 Paris, France.E mail: rotival@gmail.com

${ }^{b}$ Établissement Pharmaceutique des Hôpitaux de Paris, Laboratoire de Contrôle Qualité, 75005 Paris, France

${ }^{c}$ Laboratoire de Sciences et Méthodes Séparatives, EA 3233, IMR 4114, Université de Rouen, 76821 Mont Saint Aignan, France

${ }^{d}$ Université Bordeaux, LOMA, UMR 5798, 33400 Talence, France

${ }^{e}$ CNRS, LOMA, UMR 5798, 33400 Talence, France

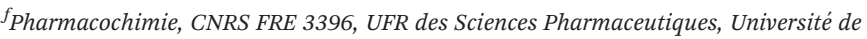
Bordeaux, 33076 Bordeaux, France

${ }^{g}$ LCRB, UMR 8015 Laboratoire de Cristallographie et RMN Biologiques, Faculté des Sciences Pharmaceutiques et Biologiques, Universite' Paris Descartes, Sorbonne Paris Cite', Faculte' des Sciences Pharmaceutiques et Biologiques, 75006 Paris, France

$\$$ Research conducted during a PhD thesis effective in the treatment of urinary retention. BC has also been used in the gastroesophageal reflux disease, ${ }^{1}$ although this therapeutic use has not yet been approved by the Food and Drug Administration. Recent research focused on the use of this drug substance in various fields. ${ }^{2-4}$ Since BC is mostly used orally, the understanding of the solid state physicochemical properties of this drug is crucial. Indeed, such properties need to be considered to design the dosage form, the manufacturing process and to apprehend stability outcomes. ${ }^{5-7}$ The difficulty of determining suitable crystallization conditions has hindered scientists from obtaining single crystals of BC. A crystal structure (monoclinic symmetry) was proposed from X-ray powder diffraction. ${ }^{8}$ The first part of the paper deals with the determination of the crystal structure from suitable single crystals. Although two polymorphs have been identified for this substance, only one has been, to date, characterized by its crystal structure. The second one has only been partially identified from commercial batches. However, it has not been isolated for better physico-chemical characterizations. Moreover, there is a lack of data in the literature regarding $\mathrm{BC}$ thermal stability, including the determination of its properties upon melting. The difficulty lies in the fact that the compound degrades during this step. Therefore, we give 
an estimation of the melting temperature and also propose a kinetic and molecular model for the description of the melting-degradation process of BC. Finally, the hygroscopic behavior of the substance will be characterized by means of Dynamic Vapor Sorption (DVS) analyses. The stability of the substance with respect to heat and to humidity will then be discussed.

\section{Materials and experiments}

\subsection{Reagents}

Bethanechol chloride (99.8\%) was purchased from Seratec (Courville-sur-Eure, France). The water content of the raw material was inferior to $0.2 \% \mathrm{w} / \mathrm{w}$ (Karl Fisher titration). Isocyanuric acid (IA), acetonitrile (ACN) and heptafluorobutyric acid (HFBA) were purchased from Sigma (Steinheim, Germany).

\subsection{Crystallization studies}

Studies on the crystallization were performed to find suitable conditions for the growth of BC single crystals. Preliminary tests using slow evaporation of $\mathrm{BC}$ organic solutions led to unsatisfactory results.

Crystallizations in solution were performed using a solvent screening procedure. The tested solvents were ultrapure water (Millipore, Saint-Quentin-en-Yvelines, France), pure methanol, ethanol, propan-1-ol, propan-2-ol and dioxane (Prolabo-VWR International SAS, Fontenay-sous-bois, France).

One gram of the compound was first mixed with $8 \mathrm{ml}$ of the pure solvents or binary combinations of them (the chosen ratios were $50: 50,70: 30$ and $97: 3 \mathrm{v} / \mathrm{v}$ ). The mixture was stirred at $35{ }^{\circ} \mathrm{C}$ and after 2 hours of equilibration, powder was added so as to obtain saturated solutions when necessary.

The supernatant was filtered through an $0.45 \mu \mathrm{m} \mathrm{GH}$ Polypro membrane filter (Gelman, Saint Germain-en-Laye, France) and cooled down to $22{ }^{\circ} \mathrm{C}$. Two different linear cooling programs were attempted from 35 to $22{ }^{\circ} \mathrm{C}$ to promote crystal growth, i.e. fast (5 min) and slow cooling (3 days).

Among all the tested conditions, suitable single crystals were obtained from a water : propan-1-ol mixture (97:3, v/v) and with the slower cooling rate.

\subsection{Solid state analysis}

The crystallographic data of bethanechol chloride were collected at $123 \mathrm{~K}$ with a R-Axis Rapid Rigaku MSC diffractometer using monochromatic $\mathrm{Cu}-\mathrm{K} \alpha$ radiation $(\lambda=$ $1.54178 \AA$ ) and a curved image plate detector. A small plate crystal of $0.08 \times 0.08 \times 0.03 \mathrm{~mm}^{3}$ was used to collect the data. The full sphere data collection was performed using $\varphi$ scans and $\omega$ scans. The unit cell determination and data reduction were performed using the Crystalclear program suite ${ }^{9,10}$ on the full set of data. The crystal structure was solved by direct methods and successive Fourier difference syntheses and refined on $F^{2}$ by weighted anisotropic full-matrix least squares methods using the SHELX97 programs suite. ${ }^{11,12}$ Each piece of software was used within WINGX. ${ }^{13,14}$ No absorption correction was needed owing to the low absorption coefficient of this compound. All the non- $\mathrm{H}$ atoms were refined with anisotropic temperature parameters. Except for the $\mathrm{H}$ of the amine moiety, the positions of the $\mathrm{H}$ atoms were deduced from coordinates of the non-H atoms, confirmed by Fourier synthesis and treated according to the riding model during refinement with isotropic displacement parameters corresponding to the atom they are linked to. These $\mathrm{H}$ atoms were included for structure factor calculations but not refined. The program OLEX $2^{15}$ was used for the analysis and drawing figures.

The crystallographic data have been deposited in the Cambridge Crystallographic Data Centre (CCDC deposition number 818326).

The high-resolution X-ray powder pattern was recorded by means of a horizontally mounted INEL cylindrical positionsensitive detector CPS120 (Artenay, France). The detector, used in Debye-Scherrer geometry (transmission mode), consists of 4096 channels and enables simultaneous recording of the diffraction profile over a $2 \theta$-range between 2 and $115^{\circ}$ (angular step of $0.029^{\circ}$ in $2 \theta$ ). Monochromatic $\mathrm{Cu}-\mathrm{K} \alpha_{1}$ radiation was selected by means of an asymmetric focusing incident-beam curved quartz monochromator. The generator power was set to $1.0 \mathrm{~kW}(40 \mathrm{kV}$ and $25 \mathrm{~mA}$ ). External calibration was performed by means of cubic spline fittings using $\mathrm{Na}_{2} \mathrm{Ca}_{2} \mathrm{Al}_{2} \mathrm{~F}_{14}$ mixed with silver behenate. The sample was placed into $0.5 \mathrm{~mm}$ diameter Lindemann capillaries. During the data collection, the capillary was rotating perpendicularly to the X-ray beam direction to minimize possible effects of preferred orientations. The high-resolution XRPD patterns were indexed using the peak-picking-option of the software package of Materials Studio Modeling 5.5 potential solutions (http://accelrys.com/ products/materials-studio) for the unit cell parameters and space group were found using the X-cell algorithm. ${ }^{16}$ The unit cell dimensions were refined using a Pawley profile-fitting procedure. ${ }^{17}$ For the structure determination, the Dreiding force field procedure ${ }^{18}$ was used to get the distances, angles and torsions in the molecule.

Thermogravimetric analyses (TGA) were performed using a TGA 850 from Mettler-Toledo (Greifensee, Switzerland) sensitive to $1 \mu \mathrm{g}$.

Differential scanning calorimetry (DSC) experiments were run with a DSC 822e thermal analyzer from Mettler-Toledo. Indium $\left(T_{\text {fus }}=156.6{ }^{\circ} \mathrm{C}, \Delta_{\text {fus }} H=28.45 \mathrm{~J} \mathrm{~g}{ }^{1}\right.$ ) was used as a standard for the temperature and enthalpy calibrations. Samples were weighed in open aluminum pans using a microbalance sensitive to $10 \mu \mathrm{g}$. For both the TGA and DSC techniques, different scanning rates varying from 2 to $50{ }^{\circ} \mathrm{C}$ $\min { }^{1}$ were performed to assess the degradation kinetics of the compound. Nitrogen was used as a purge gas in both techniques.

Thermogravimetric Analysis - Differential Scanning Calorimetry - Mass Spectrometry (TGA-DSC-MS) measurements were carried out using a NETZSCH STA 449C Jupiter apparatus (Selb, Germany) equipped with a low temperature furnace. The purge gas was helium (flow rate: $40 \mathrm{~mL} \mathrm{~min}{ }^{1}$ ) and the reference material was an empty and non-covered aluminum pan. The samples were weighed in open aluminum pans and then placed in the analyzer. PROTEUS software was used for data processing (v. 4.7.0). The chemical nature of the 
escaping gas was identified by using a Netzsch QMS $403 \mathrm{C}$ mass spectrometer coupled with the TGA-DSC apparatus.

The test for static hygroscopicity was performed according to the European Pharmacopoeia, ${ }^{19}$ starting from $500 \mathrm{mg}$ of powder.

Moisture sorption isotherms at $25{ }^{\circ} \mathrm{C}$ of the anhydrous crystalline phase were performed by a DVS-1 and a DVS Advantage Plus automated water sorption analyzer (Surface Measurement Systems, Alperton, U.K.). Mass variations of the sample ( $\sim 4 \mathrm{mg}$ ) were recorded while relative humidity $(\mathrm{RH})$ was successively increased from $0 \%$ to $90 \% \mathrm{RH}$ by successive steps. The automated analyzer was allowed to proceed with the following step as soon as the mass variation of the sample was less than $5 \times 10^{4} \% \min ^{1}$.

\subsection{Liquid chromatography-mass spectrometry analysis}

Two methods were used in the liquid chromatography (LC) with mass spectrometry (MS) detection to achieve the impurity profile of BC samples submitted to stress conditions.

The LC system (Thermoseparations Products, Fremont, CA, USA) consisted of a P4000 quaternary pump, a SCM400 vacuum degasser and an AS3000 autosampler.

For analyses in reverse phase liquid chromatography (RPLC), a Kinetex $\mathbb{R}$ C18 XB column (Phenomenex, Torrance, CA, USA) with $100 \mathrm{~mm}$ length, $2.1 \mathrm{~mm}$ internal diameter and $2.6 \mu \mathrm{m}$ particle size was used. The flow rate was $0.3 \mathrm{~mL} \mathrm{~min}{ }^{1}$, the sample injection volume was $20 \mu \mathrm{L}$ and the concentration of the injected solutions was $4 \mathrm{mg} \mathrm{mL}{ }^{1}$ expressed as bethanechol chloride. A mobile phase linear gradient was set up (solvent A: HFBA in ultrapure water $0.17 \% \mathrm{v} / \mathrm{v}$, solvent B: $\mathrm{ACN})$. At the injection time, the volume ratio A : B was set at $80: 20$, between analysis times of $2 \mathrm{~min}$ and $20 \mathrm{~min}$ it went to $10: 90$, then a return to the initial conditions was set from 20 to $30 \mathrm{~min}$. Inter-run stabilization lasted for $5 \mathrm{~min}$. The gradient was determined by taking into account late eluting impurities.

Hydrophilic interaction liquid chromatography (HILIC) was performed using a Kinetex $₫$ HILIC column (Phenomenex), $150 \mathrm{~mm}$ length, $2.1 \mathrm{~mm}$ internal diameter, and $2.6 \mu \mathrm{m}$ particle size. Elution of the impurities was performed using isocratic conditions of the mobile phase (solvent A: ACN, solvent B: ammonium acetate $100 \mathrm{mM}$ in ultrapure water, adjusted to $\mathrm{pH}$ $=6$ with acetic acid). The volume ratio $\mathrm{A}: \mathrm{B}$ was set at $95: 5$. The injection volume was $2.5 \mu \mathrm{L}$ and the concentration of injected solutions was $4 \mathrm{mg} \mathrm{ml}{ }^{1}$ expressed as bethanechol chloride.

Mass spectrometry detection consisted of a LCQ quadrupole ion trap mass spectrometer (Thermo Finnigan) and an electrospray ionization (ESI $\dagger$ ) source. The instrumental parameters of the mass spectrometer were as follows: ESI $\dagger$ the source operated in a positive ionization mode with a $4.5 \mathrm{kV}$ spray voltage and an $80 \mu \mathrm{A}$ intensity. High purity nitrogen was used as the sheath/auxiliary gas (flow rate $80: 20$ ). The capillary voltage was $3.0 \mathrm{~V}$ and its temperature was set at 270 ${ }^{\circ} \mathrm{C}$. The analysis of the impurities was achieved by scanning a mass range from 50 to 500 mass-to-charge ratio $(\mathrm{m} / \mathrm{z})$.

Tandem mass spectrometry $\left(\mathrm{MS}^{2}\right)$ studies were performed by colliding specific precursor ions with the nitrogen damping gas present in the trap for $30 \mathrm{~ms}$. The isolation width was fixed at 2.0 mass unit $(\mathrm{u})$. The product ion spectra were obtained by scanning a 50 to $500 \mathrm{~m} / \mathrm{z}$ range. The data acquisition software

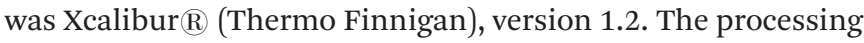

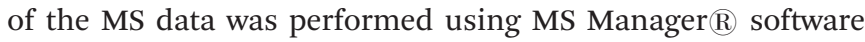
version 10 (ACD Labs, Toronto, Ontario, Canada).

\subsection{Thermal stress approach}

Samples of $\sim 3 \mathrm{mg}$ of bethanechol chloride in open aluminum pans were heated in the TGA apparatus in isothermal conditions, each $10^{\circ}$ from 150 to $200{ }^{\circ} \mathrm{C}$. The residue was analyzed at different checkpoints by HPLC analysis. Single crystals of thermal degradants were obtained by following a method previously described. ${ }^{20}$ The raw material was placed at the end of a $30 \mathrm{~cm}$ silica tube and then sealed under a secondorder vacuum. The tube was inserted into a tubular furnace with a gradient temperature of approximately $5{ }^{\circ} \mathrm{C} \mathrm{cm}{ }^{1}$. The part with the sample was placed at $165{ }^{\circ} \mathrm{C}$ and the other extremity was at room temperature for two months. Then, the single crystals obtained were analyzed by X-ray diffraction.

\section{Results and discussion}

\subsection{Solid state properties}

3.1.1. Crystal structure. The BC crystal structure has been determined from data collected on a single crystal at $123 \mathrm{~K}$. The space group was found to be $P 2_{1} / n(Z=4)$. The crystal and structure refinement data are gathered in Table 3. This crystal structure is in agreement with that previously determined by Le Bail from refinement on XRPD patterns at $298 \mathrm{~K} .{ }^{8}$ The asymmetric unit of this structure is presented in Fig. 1.

The ammonium part of the molecule presents a very regular tetrahedral geometry, with dihedral angles from 107.3(3) to $112.2(3)^{\circ}$ leading to a mean value of $109.5^{\circ}$. The corresponding N8-C distances range from 1.497(4) $\AA$ to $1.516 \AA$, as expected for single $\mathrm{N}-\mathrm{C}$ bonds with an $\mathrm{sp}^{3}$ hybridization for the central nitrogen atom. The carbamoyl group is quasi planar (H3A-N3$\mathrm{C} 2-\mathrm{O} 4$ torsion angle $=174(3)^{\circ} ; \mathrm{H} 3 \mathrm{~A}-\mathrm{N} 3-\mathrm{C} 2-\mathrm{O} 1$ torsion angle $=9(3)^{\circ}$; H3A and H3B are at $0.07(4) \AA$ and $0.20(3) \AA$ from the mean plane of N3-C2-O1-O4 (RMSD $=0.01 \AA)$ ). The N3-C2 bond length is 1.339(4) $\AA$. This value, between a pure $\mathrm{C}-\mathrm{N}$ double bond (1.28 $\AA$ ) and a C-N single bond (1.41 $\AA$ ), denotes a partial delocalization of the nitrogen electronic doublet, as expected for $\mathrm{sp}^{2}$ hybridization. According to this quasi planar geometry of the carbamoyl group and to the N3-C2 bond length, the nitrogen $\mathrm{N} 3$ was found to have essentially an $\mathrm{sp}^{2}$ hybridization. However, the deviation observed from the mean plane of the amine $\mathrm{H}$ atoms (particularly the strong deviation of $\mathrm{H} 3 \mathrm{~B})$ may feature a partial $\mathrm{sp}^{3}$ hybridization. This observation is in good agreement with the measured N3-C2 bond length. The latter is slightly higher than those observed in the CSD database for similar compounds with a carbamoyl moiety, where the $\mathrm{C}-\mathrm{N}$ distance is mainly found at around $1.33 \AA$ A.

The BC molecular conformation is achieved through two intramolecular $\mathrm{H}$-bond-like interactions between the oxygen atom of the carbonyl group and the $\mathrm{H}$ atoms from two methyl groups of the ammonium part of the molecule, i.e. H10B and 


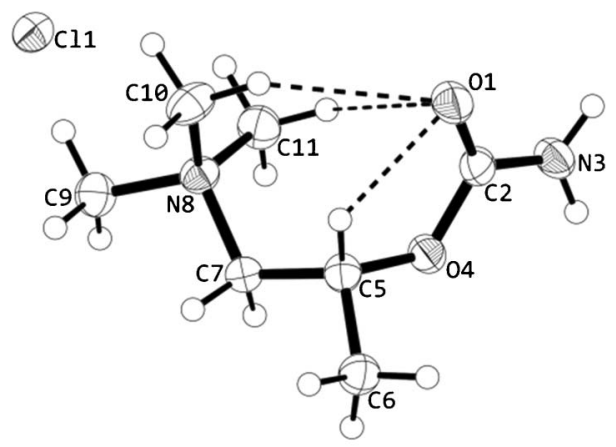

Fig. 1 ORTEP representation of the bethanechol chloride asymmetric unit. The intramolecular $\mathrm{H}$ bonds are represented by dashed lines. Displacement ellipsoids are drawn at the $50 \%$ probability level.

H11C (Fig. 1 and Table 1). This conformation is stabilized by a third intramolecular $\mathrm{H}$-bond-like interaction between $\mathrm{H} 5$ and O1, leading to a chelate effect that directs $\mathrm{H} 5$ through $\mathrm{O} 1$. This interaction cannot be defined as pure H-bonding as the C5$\mathrm{H} 5 \cdots \mathrm{O} 1$ angle is far from $180^{\circ}\left(105.9(2)^{\circ}\right)$. Nevertheless, the distance between C5 and O1 (2.698(4) $\AA$ ) is short enough to consider that this interaction stabilizes the chelate conformation.

The crystalline network cohesion is essentially ensured by two types of interactions. H-bond intermolecular interactions between the amino group and the chloride anion in the (110) direction and the carbonyl and the $\mathrm{CH}_{2}$ groups in the (001) direction (Table 2), and electrostatic interactions between each methyl of the ammonium group and the chloride anion (Fig. 2).

The lattice parameters and some selected geometrical data obtained from the single crystal X-ray measurements are gathered in Table 3 and compared with the data obtained from the X-ray powder diffraction (XRPD).

The available raw material was analyzed by XRPD. A refinement was performed using a high resolution pattern recorded at $298 \mathrm{~K}$ (Table 3). The final Rietveld refinement from our results, including Pawley-refined parameters, converged to a final $R_{\mathrm{WP}}=4.22 \%$, instead of the $7.39 \%$ obtained by Le Bail. ${ }^{8}$ The space group and cell parameters determined from the fitting of the powder diffraction pattern of the raw material are in good agreement with the ones obtained for the single crystal (Fig. 3).

A comparison of the cell parameters obtained at 123 and 298 $\mathrm{K}$ shows that the thermal expansion of the BC crystals occurs along the three axes. It should be noticed that the temperature discrepancy affects neither the conformation of the molecules

Table 1 Intramolecular hydrogen bond geometry $\left(\AA,^{\circ}\right)$

\begin{tabular}{lllll}
\hline $\mathrm{D} \mathrm{H} \cdots \mathrm{A}$ & $\mathrm{D} \mathrm{H}$ & $\mathrm{H} \cdots \mathrm{A}$ & $\mathrm{D} \cdots \mathrm{A}$ & $\mathrm{D} \mathrm{H} \cdots \mathrm{A}$ \\
\hline $\mathrm{C} 5 \mathrm{H} 5 \cdots \mathrm{O} 1$ & 1.00 & 2.244 & $2.697(4)$ & 106.06 \\
$\mathrm{C} 10 \mathrm{H} 10 \mathrm{~B} \cdots \mathrm{O} 1$ & 0.98 & 2.580 & $3.459(6)$ & 149.49 \\
$\mathrm{C} 11 \mathrm{H} 11 \mathrm{C} \cdots \mathrm{O} 1$ & 0.98 & 2.651 & $3.514(4)$ & 147.00
\end{tabular}

Table 2 Intermolecular hydrogen bond geometry $\left(\AA,^{\circ}\right)$

\begin{tabular}{|c|c|c|c|c|}
\hline $\mathrm{D} H \cdots \mathrm{A}$ & D H & $\mathrm{H} \cdots \mathrm{A}$ & $\mathrm{D} \cdots \mathrm{A}$ & $\mathrm{D} H \cdots \mathrm{A}$ \\
\hline N3 $\mathrm{H} 3 \mathrm{~B} \cdots \mathrm{Cl}^{\mathrm{i}}$ & 0.88 & 2.578 & $3.290(3)$ & 138.64 \\
\hline N3 $\mathrm{H} 3 \mathrm{~A} \cdots \mathrm{Cl}^{\mathrm{ii}}$ & 0.88 & 2.397 & $3.271(3)$ & 172.14 \\
\hline C7 $\mathrm{H} \mathrm{A} \cdots \mathrm{O} 1^{\mathrm{iii}}$ & 0.99 & 2.384 & $3.274(4)$ & 149.26 \\
\hline
\end{tabular}

in the crystal network, nor the intramolecular bond lengths and angles.

The bond lengths and angle values, obtained from single crystal X-ray diffraction, were compared to the ones obtained from the X-ray powder diffraction in ref. 8. Three main inconsistencies can be highlighted with respect to intramolecular bindings: (i) the N8-C bond lengths and angles related to the tetrahedral quaternary ammonium moiety are more coherent when they are determined from the single crystal $\mathrm{X}$-ray diffraction experiment, i.e. bond lengths are close to $1.5 \AA$ and angles $\sim 109^{\circ}$, (ii) the $\mathrm{O} 4{ }^{\cdots} \mathrm{C}_{X}$ bond lengths are higher than the corresponding ones previously determined and are in good agreement with the reported values found for other carbamate structures, ${ }^{21-24}$ and (iii) the torsion angles of the carbamate residue determined from the monocrystal accurately reflect that its geometry is quasi planar.

Interestingly, the $\mathrm{H}$ atoms position in $\mathrm{NH}_{2}$ was improved by energy minimization. The corresponding $\mathrm{H}$ atom positions were fully refined according to the single crystal measurement data. Thus, they were not set in the $\mathrm{sp}^{2}$ position. It is worth noting that the slight $\mathrm{sp}^{3}$ hybridization found via the energyminimization calculation is in good agreement with the single crystal results (see Section 3.1.1.).

3.1.2. Thermodynamic properties. The thermodynamic data related to $\mathrm{BC}$ available in the literature are contradictory. Indeed, the Merck index gives a decomposition temperature for $\mathrm{BC}$ at $218-219{ }^{\circ} \mathrm{C}$, whereas the Japanese Pharmacopoeia

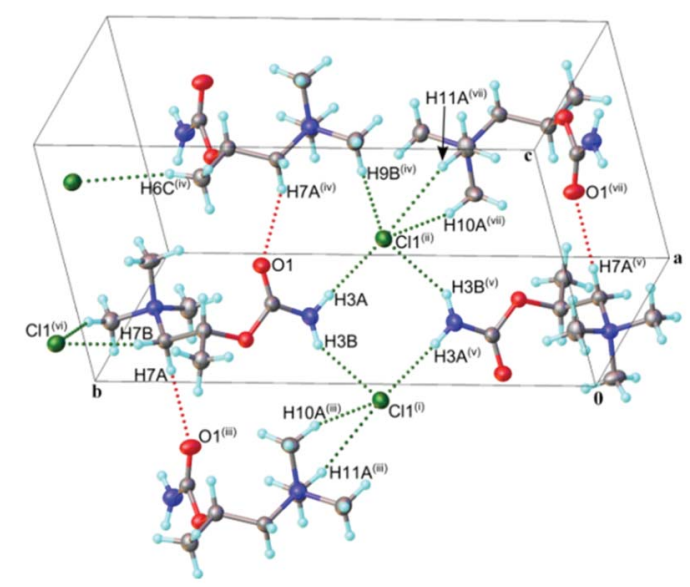

Fig. 2 Selected $\mathrm{H}$ bond type intermolecular contacts in the crystal lattice of $\mathrm{BC}$. Symmetry codes: (i) $1 / 2 \quad x_{1} 1 / 2+y_{1} 1 / 2 \quad z_{\text {; }}$ (ii) $1 / 2+x_{1} 3 / 2 \quad y_{1} \quad 1 / 2+z_{\text {; }}$ (iii) $1 / 2+x, 3 / 2 \quad y_{1} \quad 1 / 2+z_{i}$ (iv) $1 / 2+x, 3 / 2 \quad y, 1 / 2+z_{i}$ (v) $1 \quad x, 1 \quad y_{\text {, }}$ $z_{i}$ (vi) $x, 2 \quad y, 1 \quad z ;$ (vii) $3 / 2 \quad x, 1 / 2+y, 1 / 2 \quad z$. 
Table 3 Lattice parameters and selected geometrical data obtained from single crystal and powder resolutions

\begin{tabular}{|c|c|c|c|c|}
\hline & & Powder $298 \mathrm{~K}\left(\AA{ }^{\circ}{ }^{\circ}\right)$ ref. 8 & Powder $298 \mathrm{~K}\left(\AA{ }^{\circ}{ }^{\circ}\right)$ this work & Single crystal $123 \mathrm{~K}\left(\AA^{\circ},{ }^{\circ}\right)$ this work \\
\hline \multirow[t]{5}{*}{ Cell parameters } & $a$ & $7.1373(3)$ & $7.1359(4)$ & $7.0933(6)$ \\
\hline & $b$ & $16.4118(7)$ & $16.4127(9)$ & $16.2066(11)$ \\
\hline & $c$ & $8.8749(3)$ & $8.8740(5)$ & $8.8042(7)$ \\
\hline & $\beta$ & $93.803(1)$ & $93.830(3)$ & $93.749(3)$ \\
\hline & Resolution index & $R_{\mathrm{WP}} \quad 0.0707$ & $R_{\mathrm{WP}} \quad 0.0422$ & $R \quad 0.0739, w R$ \\
\hline \multirow[t]{8}{*}{ Ammonium IV } & N8 C10 & $1.56(1)$ & 1.492 & $1.496(4)$ \\
\hline & N8 C11 & $1.45(1)$ & 1.499 & $1.499(5)$ \\
\hline & N8 C9 & $1.50(9)$ & 1.506 & $1.501(5)$ \\
\hline & N8 C7 & $1.49(2)$ & 1.545 & $1.516(4)$ \\
\hline & C10N8C9 & $102.4(7)$ & 108.9 & $108.1(3)$ \\
\hline & C10N8C11 & $104.3(7)$ & 113.6 & $110.0(3)$ \\
\hline & C9N8C11 & $108.5(7)$ & 108.3 & $107.3(3)$ \\
\hline & C10N8C7 & $108.6(8)$ & 111.8 & $111.8(3)$ \\
\hline \multirow[t]{4}{*}{ Asymmetric carbon } & O4C5C6 & $117.2(9)$ & 109.4 & $108.1(3)$ \\
\hline & O4C5H5 & $94(1)$ & 111.9 & 109.8 \\
\hline & O4C5C7 & $109(1)$ & 111.9 & $110.2(3)$ \\
\hline & C6C5C7 & $104.4(9)$ & 106.9 & $109.3(3)$ \\
\hline \multirow[t]{4}{*}{ Carbamate } & $\mathrm{O} 4 \mathrm{C} 2$ & $1.28(1)$ & 1.370 & $1.359(4)$ \\
\hline & $\mathrm{C} 5 \mathrm{O} 4$ & $1.39(9)$ & 1.430 & $1.454(4)$ \\
\hline & $\mathrm{C} 5 \mathrm{O} 4 \mathrm{C} 2 \mathrm{~N} 3$ & $173(1)$ & 175.99 & $178.7(3)$ \\
\hline & C5O4C2O1 & $-13(2)$ & -2.57 & $-4.2(5)$ \\
\hline
\end{tabular}

reports two melting points $\left(211\right.$ and $\left.219^{\circ} \mathrm{C}\right)$, indicating solid

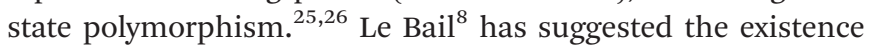
of an orthorhombic form of $\mathrm{BC}$, discovered in as-received $\mathrm{BC}$ samples containing mainly the monoclinic form. As noted by the author, after a few weeks of annealing at room temperature, these samples transformed into the monoclinic stable phase. The indexing in the orthorhombic cell was carried out by removing the peaks from the monoclinic form. However, the orthorhombic form could not have been isolated. Therefore, its crystal structure has not been solved. With regard to the discussion held by the author, this phase was assumed to be stable at higher temperature, implying an enantiotropic relationship with the monoclinic stable form, although he did not identify the DSC signals of any thermal event corresponding to such a transition. ${ }^{8}$ As far as we are

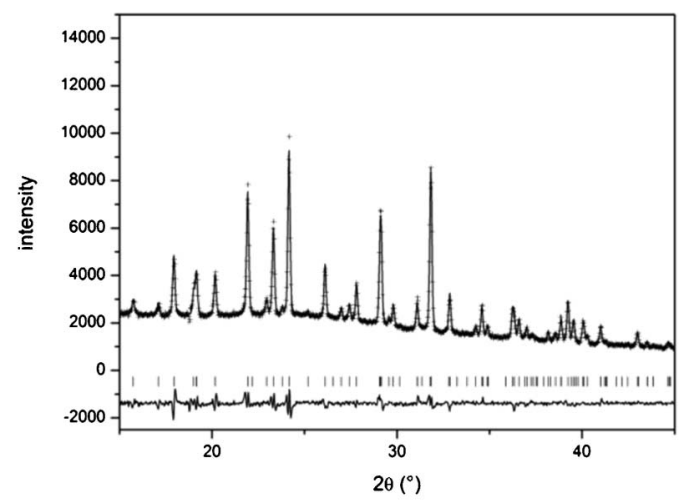

Fig. 3 Final Rietveld refinement of the $X$ ray diffraction pattern of bethanechol chloride, obtained for the raw material at room temperature (solid line: experimental data, cross line: Rietveld refinement). concerned, despite various crystallization attempts, this second polymorph has never been seen.

DSC and TGA experiments were performed on the raw material (pure monoclinic form) under different heating conditions. In Fig. 4, typical DSC and TGA curves conducted at two different heating rates are presented. Whatever the heating rate, two endothermic phenomena are present: the first one has an onset temperature $\left(214\right.$ or $222{ }^{\circ} \mathrm{C}$ at 5 or $10{ }^{\circ} \mathrm{C}$ $\min { }^{1}$, respectively) close to the melting point reported in the literature $^{25}$ but is associated to a significant mass loss $(\sim 6 \%$ for both heating rates). One can assume that this thermal event corresponds to a concomitant melting-decomposition

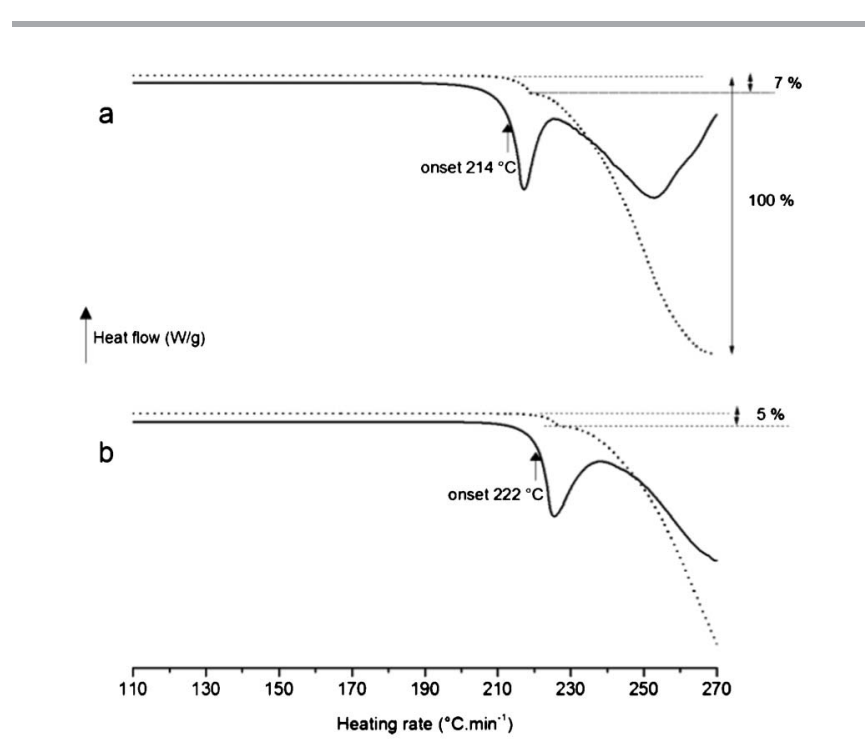

Fig. 4 DSC and TGA thermograms of bethanechol chloride in open pans (solid line: heat flow, dashed line: sample weight). Scan rate: (a) 5 , and (b) $10{ }^{\circ} \mathrm{C}$ $\min ^{-1}$. 

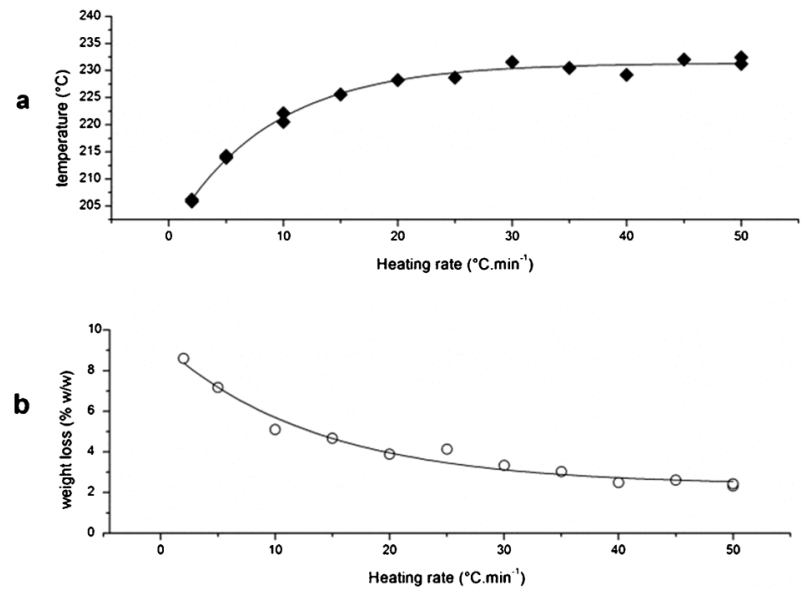

Fig. 5 Onsets of the first endothermic phenomenon and associated weight loss as a function of the heating rate of BC. Curve fitting results: $y=31.6{ }^{*} \exp (x /$ $8.7)+231.4, R^{2}=0.992(a)$, and $y=7.0{ }^{*} \exp (x / 13.5)+2.4, R^{2}=0.980(b)$

process. The second endothermic phenomenon is important and associated with a significant weight loss (up to $100 \%$ ) and can be attributed to a decomposition-evaporation process.

A full analysis focused on the first thermal event for DSC and TGA performed between 2 and $50{ }^{\circ} \mathrm{C}$ min ${ }^{1}$ indicates that the recorded onset temperature increases and the associated weight loss decreases when increasing the scanning rate (Fig. 5). The transformation of the solid sample during this first thermal event is kinetically driven. This kinetic dependence is clearly pronounced for heating rates inferior to $15{ }^{\circ} \mathrm{C}$ min ${ }^{1}$, whereas the onset temperature and the weight loss seem to be stabilized for heating rates superior to $30^{\circ} \mathrm{C} \mathrm{min}{ }^{1}$. Assuming that the endothermic signal is due to a meltingdecomposition process, the increase of the onset value and the decrease of the associated weight loss both reflect that the decomposition during melting is minimized at high heating rates. $^{27}$ As a consequence, the best evaluation for the $\mathrm{BC}$ melting temperature is $231.4 \pm 0.4{ }^{\circ} \mathrm{C}$, i.e. the value reached by the onset temperature at high heating rates.

However, the decomposition process cannot be avoided during melting as $\sim 2 \%$ of the mass loss is still seen even at 50 ${ }^{\circ} \mathrm{C}$ min ${ }^{1}$. The corresponding mechanism of melting degradation involved during the heating of $\mathrm{BC}$ is presented in the following section.

Besides, it is noteworthy that when starting from the monoclinic phase (i.e. the stable form at room temperature), no transition into the orthorhombic phase was observed. In addition, as reported in ref. 8, when the two polymorphs are mixed at room temperature, the orthorhombic polymorph transforms spontaneously into the monoclinic one, which clearly demonstrates that the latter form is the thermodynamically stable phase at ambient conditions. These results suggest that there is a monotropic relationship between the two phases. Some complementary experiments, such as solubility measurements, could support this interpretation but the accessibility to the pure orthorhombic form is, up to now, not possible.

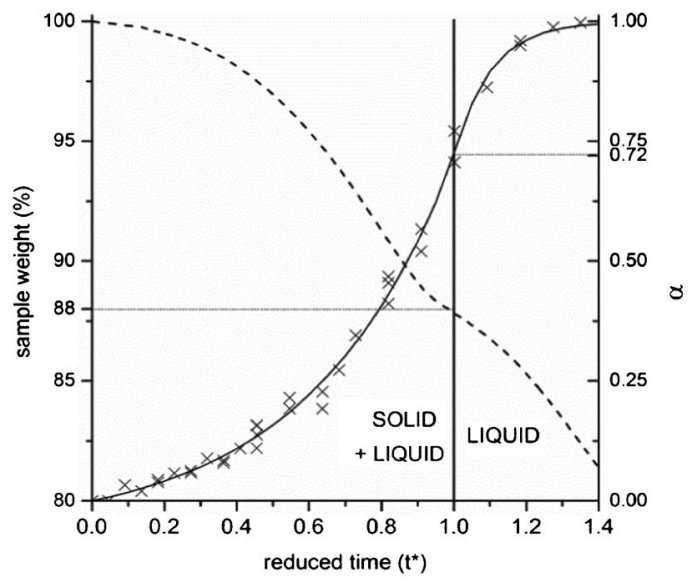

Fig. 6 TGA data (dashed line), HPLC assay results and the related Bawn fitting data (solid line) obtained for BC at $200{ }^{\circ} \mathrm{C}$.

\subsection{Thermal stability of bethanechol chloride}

3.2.1. Overall reaction. The $\mathrm{BC}$ melting-decomposition process was studied in open pans and dry conditions at 200 ${ }^{\circ}$ C. LC-MS analyses of the solid sample allow for the determining of both the extent of degradation and the impurity profile. TGA-DSC-MS analysis allowed us to monitor the volatile compounds. The extent of the chemical degradation measured by liquid chromatography $(\alpha \mathrm{LC}, \mathrm{mol} / \mathrm{mol})$ was determined as follows:

$$
\alpha \mathrm{LC}_{t}=\left(\begin{array}{ll}
q_{\mathrm{i}} & q_{t}
\end{array}\right) / q_{\mathrm{i}}
$$

where $q_{t}$ is the quantity of bethanechol chloride expressed in $\mathrm{mg}$ at a given time $t$, and $q_{\mathrm{i}}$ is the quantity of bethanechol chloride initially present in the sample (i.e. at $t_{0}$ ).

The $\alpha \mathrm{LC} v s$. time curve is a sigmoid, as can be seen in Fig. 6. The inflexion point of the latter curve has been found at $t^{*}=$ 22.0 minutes, $\alpha^{*}=0.72$. The parameters of the sigmoid fitting are provided in Section 3.2.2. Besides, one can see that the TGA signals have a two-step profile similar to those previously obtained for non isothermal conditions. The first step of the weight loss $(12 \% \mathrm{w} / \mathrm{w})$ detected in the TGA analysis correlates at $t^{*}$ with the inflexion point of the sigmoid curve. Furthermore, thermomicroscopy experiments highlighted a gradual melting and the formation of an apparent homogeneous liquid phase at $t^{*}$. It can be seen in Fig. 7 that solid particles are visible at $t=0.7 t^{*}$, as well as the formation of bubbles. Consequently, BC liquefaction occurs between $t=0$ and $t=t^{*}$.

The chromatographic analysis showed that two distinguishable profiles can be found on either side of the liquefaction point, $t^{*}$ (Fig. 8). The main thermal degradants detected below and above the liquefaction point have been denoted as early (E) and late (L) degradants, respectively. Up to the liquefaction point, bethanechol is mainly converted to impurity E1. As a matter of fact, the two latter compounds have similar retention times, E1 being eluted before bethanechol. E1, with a $\mathrm{m} / \mathrm{z}$ signal at 118, was assigned as betamethylcholine by standard 

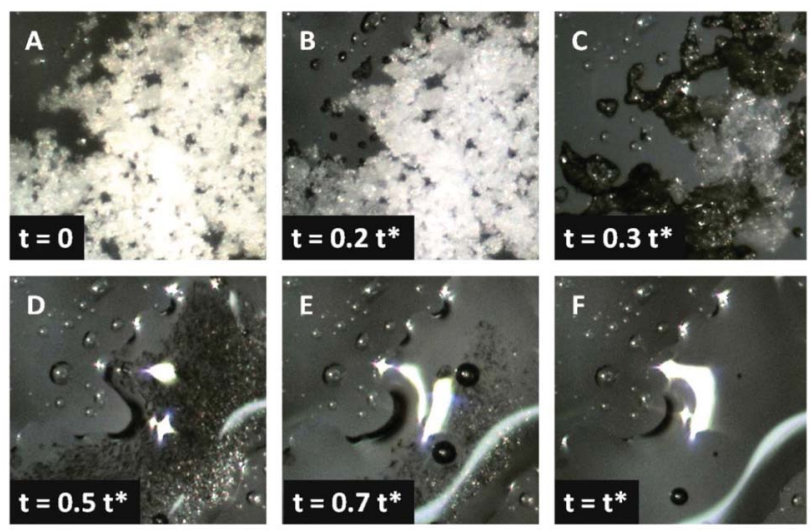

Fig. 7 Thermomicroscopy images of a sample placed in an open chamber at $200{ }^{\circ} \mathrm{C}$.

injection. Indeed, the thermal decomposition of carbamates induces the formation of alcohol and isocyanic acid (IA). ${ }^{28}$ This is corroborated by the signal at $\mathrm{m} / \mathrm{z} 43$ obtained from the TGA-MS analysis and corresponds to the molecular mass of isocyanic acid. These results indicate that the liquefaction reaction mainly consists of the progressive dissolution of bethanechol chloride in its liquid degradant, namely beta-
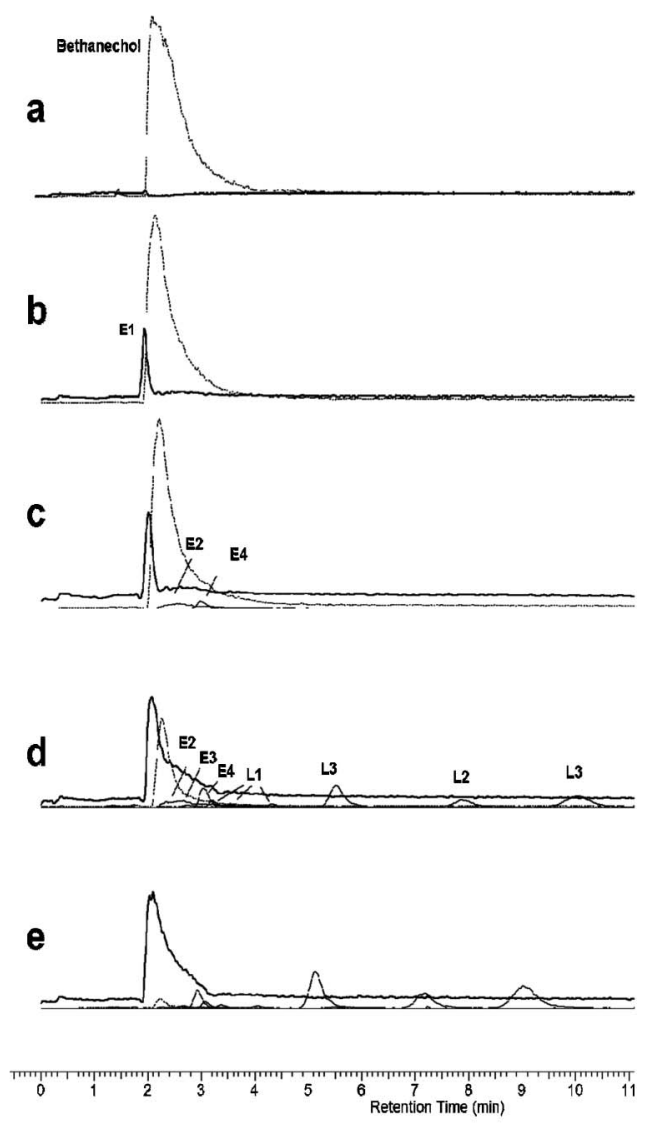

Fig. 8 Evolution of the LC MS signal as a function of time at $200{ }^{\circ} \mathrm{C}$ (a: $t_{0}$, b: 0.4 $\left.t^{*}, \mathrm{c}: 0.7 t^{*}, \mathrm{~d}: t^{*}, \mathrm{e}: 1.2 t^{\star}\right)$.

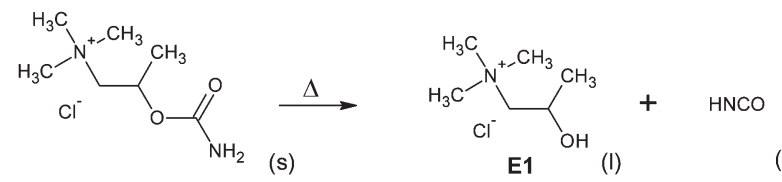

(g)

Fig. 9 Thermal decomposition of bethanechol chloride into bethamethylcholine chloride and isocyanic acid (s: solid, l: liquid, g: gas).

methylcholine chloride (melting point: $165^{\circ} \mathrm{C}$ ), as it is described in Fig. 9. The nature of the products detected and involved in the decomposition pathways are discussed in Section 3.2.3.

3.2.2. Decomposition kinetics. It is worth considering that the two-step process encountered during the melting decomposition of $\mathrm{BC}$ in betamethylcholine chloride is in accordance with the reaction model: solid $\rightarrow$ (liquid + gas), as described by Bawn $^{29}$ and further promoted by Carstensen ${ }^{6}$ and Brown. ${ }^{30}$ This model may be applied when the degradant is a liquid in which the reactant is dissolved. The overall decomposition of the substance occurs both in the solid and liquid states. The liquefaction point corresponding to the total dissolution of the solid is determined at the inflexion point of the curve. The first step $\left(0<\alpha<\alpha^{*}\right)$ consists of the progressive dissolution of the entire solid phase in the liquid degradant with the solubility $S$. For a given $\alpha$, the fractions of the reactant in the liquid and solid phases are $\alpha S$ and $1 \quad \alpha \quad \alpha S$, respectively.

The rate of decomposition corresponds to the sum of the BC decomposition rate in the liquid state $\left(k_{1}\right)$ and in the solid phase $\left(k_{\mathrm{s}}\right)$ as follows:

$$
\mathrm{d} \alpha / \mathrm{d} t=k_{\mathrm{s}}(1 \quad \alpha \quad \alpha S)+k_{\mathrm{l}} S \alpha=k_{\mathrm{s}}+K \alpha
$$

where,

$$
K=k_{1} s \quad k_{\mathrm{S}} s \quad k_{\mathrm{S}}
$$

Integration of eqn (2) yields:

$$
\alpha=\left(k_{\mathrm{S}} / K\right)(\exp (K t) \quad 1)
$$

The parameters calculated from the Bawn model are presented in Table 4 . From 0 to $t^{*}$, the curve has been fitted using the latter model following the method detailed by Carstensen. ${ }^{6}$ It is worth noting that the correlation coefficient obtained with the HPLC method is lower than the ones obtained with the TGA analysis. This observation can be explained by the fact that the HPLC assay, being indirect, may increase the variability of the result. After that, the possibility of using the TGA results to directly follow the reaction was considered. As IA has been previously identified as the main evolved gas during the first steps of the reaction, the extent of the reaction ( $\alpha \mathrm{TGA}, \mathrm{mol} / \mathrm{mol}$ ) was determined as the IA quantity released, in moles, divided by the initial BC quantity, also expressed in moles (eqn (5)).

$$
\alpha \mathrm{TGA}_{t}=n(\mathrm{IA})_{t} / n(\mathrm{BC})_{\mathrm{i}}=\left[\left(m_{\mathrm{i}} \quad m_{t}\right) \times M(\mathrm{BC})\right] /\left[m_{\mathrm{i}} \times M(\mathrm{IA})\right](5)
$$




\begin{tabular}{|c|c|c|c|}
\hline Parameter & Signification & $\begin{array}{l}\text { Determination by the HPLC } \\
\text { method }(0<\alpha<1)\end{array}$ & $\begin{array}{l}\text { Determination by the TGA } \\
\text { method }(0<\alpha<0.30)\end{array}$ \\
\hline$t^{*}$ & Value of $t$ at the liquefaction point (h) & 0.37 (curve determination) & 0.37 (curve determination) \\
\hline$\alpha^{*}$ & Value of $\alpha$ at the liquefaction point ( $\mathrm{mol} / \mathrm{mol})$ & 0.72 (curve determination) & Not applicable \\
\hline \multirow{5}{*}{$\begin{array}{l}S \\
\alpha\end{array}$} & Solubility of the reactant in the product $(\mathrm{mol} / \mathrm{mol}) S\left(1-\alpha^{*}\right) / \alpha^{*}$ & \multirow[t]{2}{*}{0.39} & \multirow[t]{2}{*}{ Not applicable } \\
\hline & Extend of degradation $(\mathrm{mol} / \mathrm{mol})$ & & \\
\hline & From $t \quad 0$ to $t \quad t^{*}$ & $R^{2} \quad 0.982$ & $R \quad 0.998$ \\
\hline & $\alpha \quad\left(k_{\mathrm{S}} / K\right)(\exp K t-1)$ & \multirow[t]{2}{*}{$R^{2} \quad 0.981$} & \multirow[t]{2}{*}{ Not applicable } \\
\hline & $\begin{array}{l}\text { From } t^{*} \text { to end of reaction } \\
(1-\alpha) /\left(1-\alpha^{*}\right) \quad \exp \left[-k_{1}\left(t-t^{*}\right)\right]\end{array}$ & & \\
\hline$K$ & $\begin{array}{l}\text { Overall decomposition constant }\left(\mathrm{h}^{1}\right) \\
K \quad k_{1} s-k_{\mathrm{S}} s-k_{\mathrm{S}}\end{array}$ & 8.39 & 8.57 \\
\hline$k_{1}$ & Decomposition constant (liquid state) $\left(\mathrm{h}^{1}\right)$ & 22.92 & Not applicable \\
\hline$k_{\mathrm{S}}$ & Decomposition constant (solid state) $\left(\mathrm{h}^{1}\right)$ & 0.3770 & 0.3756 \\
\hline \multirow[t]{2}{*}{$B$} & Bawn constant & \multirow[t]{2}{*}{22.26} & 22.82 \\
\hline & $B \quad K / k_{\mathrm{S}} \quad k_{1} / k_{\mathrm{S}} s-s-1$ & & \\
\hline
\end{tabular}

where $m_{\mathrm{i}}$ is the initial sample mass, $m_{t}$ the sample mass at a given time and $M$ the molecular mass of the compound.

As shown by the comparison of the resulting kinetic parameters (Table 4), $\alpha$ TGA as a function of time is in good agreement with $\alpha$ LC. From $\alpha=0.30$, the two values diverge, suggesting that the secondary decomposition pathways may be considered as significant. As expected, the goodness of fit is significantly improved with the TGA direct determination. Consequently, the Bawn model appears to be suitable to describe the reaction, and TGA analysis can be used as a direct method to follow the early decomposition of the solid.

An assessment of the decomposition at different temperatures allows us to determine the activation energy of the reaction. For this purpose, the rate of decomposition was determined for temperatures between 150 and $200{ }^{\circ} \mathrm{C}$, using the Bawn model and the Arrhenius law (eqn (6) and (7)).

$$
\begin{gathered}
K=A \exp (E / R T) \\
k_{\mathrm{s}}=A_{\mathrm{s}} \exp \left(E_{\mathrm{s}} / R T\right)
\end{gathered}
$$

where $K$ is the overall decomposition constant, $k_{\mathrm{S}}$ is the decomposition constant in the solid state, $A$ and $A_{\mathrm{s}}$ are the frequency factors related to the overall reaction and the solid state, respectively, and $E$ and $E_{\mathrm{s}}$ correspond to the activation energies for the overall reaction and the solid state reaction, respectively.

The data obtained at each temperature were suitably fitted by eqn (6) and (7) $\left(R^{2}>0.995\right)$. Table 5 presents the thusobtained parameters. The activation energies found this way are in accordance with the thermal decomposition data obtained for other drugs. ${ }^{6}$ At lower temperatures, no liquid phase may be present and the decomposition rate would be overestimated. Nevertheless, it is worth considering that by using the Arrhenius type pot, the calculated decomposition is lower than $0.1 \%$ after 5 years of storage at $40{ }^{\circ} \mathrm{C}$. BC may thus be considered as thermally stable at ambient temperature and under dry conditions.

In the second step, from $t^{*}$ to total decomposition $\left(\alpha^{*}<\alpha\right.$ $<1$ ), the system is in the liquid state and the Bawn kinetics cannot be applied anymore. The asymmetry of the $\alpha$-sigmoidal curve obtained at $200{ }^{\circ} \mathrm{C}$ highlights a significant acceleration of the decomposition rate beyond the liquefaction point $\left(\alpha^{*}>\right.$ 0.5 ). The higher mobility of the molecules in the liquid phase increases the drug substance decomposition since $k_{1}$ is much higher than $k_{\mathrm{S} .}{ }^{30}$ An autocatalysic process probably takes part in the acceleratory effect.

As a matter of fact, various decomposition products can be detected beyond the liquefaction point, suggesting that complex decomposition processes may be involved.

3.2.3. Chemical degradation pathways. Since the room temperature raw material has a purity of at least $99.8 \%$, all the decomposition products are necessarily formed upon heating. Therefore, a structural study of these impurities is needed in order to understand the mechanism involved for the compound decomposition and to establish a comprehensive drug stability profile. ${ }^{31}$ The detected decomposition products and their relative abundance at the liquefaction point are given in Table 6. $\mathrm{MS}^{2}$ fragmentation experiments were performed for bethanechol and the impurities. The corresponding spectra (see the ESI $\dagger$ ) allowed us to achieve structural elucidation for these compounds. Bethanechol exhibits a

\begin{tabular}{|c|c|c|c|c|c|c|c|c|c|c|c|c|}
\hline & \multicolumn{7}{|c|}{ Bawn fitting } & \multicolumn{5}{|c|}{ Arrhenius law } \\
\hline & & $150{ }^{\circ} \mathrm{C}$ & $160^{\circ} \mathrm{C}$ & $170{ }^{\circ} \mathrm{C}$ & $180{ }^{\circ} \mathrm{C}$ & $190{ }^{\circ} \mathrm{C}$ & $200{ }^{\circ} \mathrm{C}$ & $\begin{array}{l}y \text { Intercept } \\
(\ln \mathrm{A})\end{array}$ & $\begin{array}{l}\text { Slope } \\
\left(-E_{\mathrm{a}} / R\right)\end{array}$ & $A\left(\mathrm{~h}^{1}\right)$ & $\begin{array}{l}E_{\mathrm{a}} \\
\left(\text { kcal mol }^{1}\right)\end{array}$ & $R^{2}$ \\
\hline Solid state decomposition & $k_{\mathrm{S}}\left(\mathrm{h}^{1}\right)$ & 0.006 & 0.010 & 0.024 & 0.057 & 0.132 & 0.376 & 33.92 & -16619 & $5.39 \times 10^{14}$ & 33.0 & 0.985 \\
\hline Overall decomposition & $K\left(\mathrm{~h}^{1}\right)$ & 0.104 & 0.347 & 0.889 & 1.986 & 5.382 & 8.572 & 40.05 & -17841 & $2.44 \times 10^{17}$ & 35.5 & 0.993 \\
\hline
\end{tabular}

Table 5 Kinetics and thermodynamic parameters of BC decomposition determined during isothermal experiments 


\begin{tabular}{|c|c|c|c|c|}
\hline & Detection method & Label & $m / z$ signal & Abundance at $t^{*}$ \\
\hline Bethanechol chloride & RP HPLC, ESI+ & & 161.1 & $28 \%$ \\
\hline \multirow[t]{8}{*}{ Early degradants } & RP HPLC, ESI+ & E1 & 118.2 & $56 \%$ \\
\hline & & E2 & 147.1 & $4 \%$ \\
\hline & & E3 & 204.2 & $<2 \%$ \\
\hline & & E4 & 175.0 & $3 \%$ \\
\hline & HILIC, ESI- & E5 & 128.2 & $<2 \%$ \\
\hline & & $\mathrm{E} 6,7,8$ & 142.1, 156.1, 170.1 & $<2 \%$ \\
\hline & TGA MS & & 43 & n.d. \\
\hline & & & 50 & n.d. \\
\hline Late degradants & RP HPLC, ESI+ & L1, L2, L3 & $229,243,257$ & $11 \%($ sum $)$ \\
\hline
\end{tabular}

ESI+/-: electrospray ionization in positive/negative mode, n.d.: not determined.

signal at $m / z$ 161. The major route of bethanechol fragmentation takes place through $\mathrm{C}-\mathrm{N}$ bond cleavage. The fragments at $\mathrm{m} / \mathrm{z} 60$ and 102 are reckoned to be the quaternary ammonium and the chain including the carbamate, respectively. $\mathrm{C}-\mathrm{O}$ bond cleavage is also evidenced by the fragment at $\mathrm{m} / \mathrm{z} 100$. The $\mathrm{m} / \mathrm{z}$ 59 signal corresponds to both $\mathrm{C}-\mathrm{N}$ and $\mathrm{C}-\mathrm{O}$ cleavage.

The molecular ion of $\mathrm{E} 2$ is at $\mathrm{m} / \mathrm{z} 147$, presenting a $14 \mathrm{u}$ difference compared to the bethanechol molecule. A common fragment at $m / z \quad 102$ shows the integrity of the chain. Additionally, detection of the fragment at $\mathrm{m} / \mathrm{z} 86$ exhibits a $14 \mathrm{u}$ difference with bethanechol. Therefore, E2 has been assigned as demethyl bethanechol. This degradation route was confirmed by the detection of methyl chloride at $\mathrm{m} / \mathrm{z} 50$ by TGA-MS analysis.

E3 is characterized by a protonated molecule at $\mathrm{m} / \mathrm{z}$ 204.2. Detection of a fragment at $\mathrm{m} / z 161$ suggests that the structure is related to bethanechol. Indeed, comparison with the bethanechol $\mathrm{MS}^{2}$ spectra shows that an increment of $43 \mathrm{u}$ is found on each bethanechol fragment comprising the carbamate moiety. This difference in mass is coherent with the addition of an isocyanic acid molecule on the bethanechol structure. Consequently, E3 has been identified as bethanechol allophanate. The formation of this compound agrees with previous observations on the thermal degradation of carbamates, ${ }^{28}$ and evidences a beginning of polymerization.

E4 exhibits a signal at $m / z 175$. The detection of common fragments with bethanechol at $\mathrm{m} / \mathrm{z} 59,60$ and 100 indicates that these two structures are closely related and that the difference is located on the carbamate moiety. The signal difference proves that $\mathrm{E} 4$ results from $N$-methylation of the primary amine. This pathway is explained by the presence of methylene chloride, which is a powerful methylating agent.

It is worth considering that $\mathrm{BC}$ decomposition leads to the formation of betamethylcholine and demethyl-bethanechol, as well as the isocyanic acid and methylene chloride gases. All these compounds further react with intact bethanechol molecules to give bethanechol allophanate and $N$-methyl bethanechol, respectively (Fig. 10). The reactive nature of the evolved gas thus confers an autocatalytic property to the reaction.

HILIC analyses in a negative ionization mode evidenced the presence of 4 other degradants denoted E5 to E8. E5 is the most abundant among them, although it is detected in trace levels. The MS spectrum of E5 shows a molecular ion at $\mathrm{m} / \mathrm{z}$ 128. Isocyanuric acid was assigned to E5 through correlation with the $\mathrm{MS}^{2}$ fragmentation pattern of a corresponding standard. This impurity is known to result from the cyclization of isocyanic acid.

Furthermore, the $\mathrm{m} / \mathrm{z}$ signals of E5 to E8 show a difference of $14 \mathrm{u}$ from one another. The analysis of the fragmentation pattern of E6, E7 and E8 allows us to conclude that their structures correspond to mono-, di- and trimethyl isocyanuric acid, respectively. These impurities may proceed from methylation of E5. A concerted mechanism must also be considered for the formation of E5 and its methylated derivatives. It involves a total of 3 molecules of bethanechol and/or $N$-methyl bethanechol and yields betamethylcholine (Fig. 11). Obviously, the latter mechanism would involve high molecular mobility, implying that it might take place primarily in the liquid phase.

Besides, in order to evaluate the thermal stress consequences, long term storage of the powder was performed under a second-order vacuum, as described in the experimental part. Depending on the gradient temperature, different degradation products condensed all along the tube. Although most of the thus-obtained products were in an amorphous state, the crystalline part was isolated and analyzed by single crystal X-ray diffraction. The crystal structure was then determined and identified as the impurity E8, which crystal-
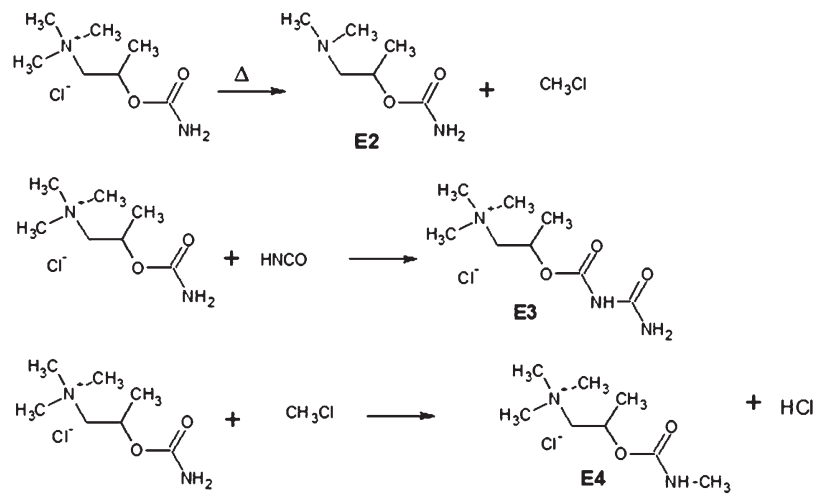

Fig. 10 Main thermal degradation pathways proposed after MS analysis. 


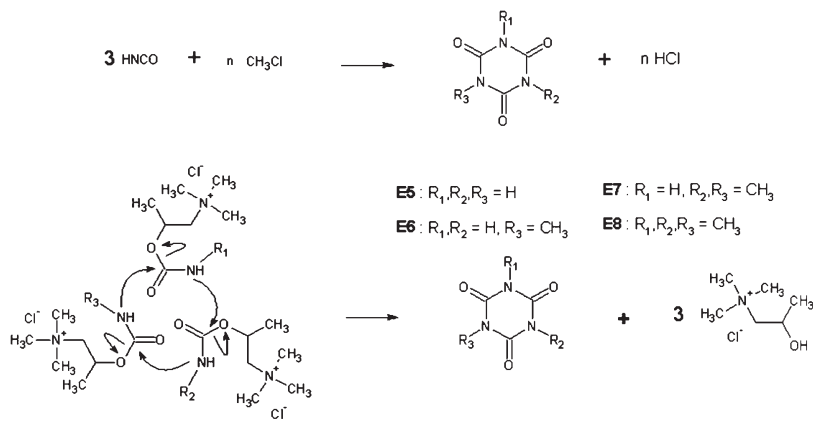

Fig. 11 Pathways proposed for the formation of isocyanic derivatives (E5 to E8).

lizes in a monoclinic system, as previously reported. ${ }^{32}$ This result confirms the occurrence of the described decomposition pathway at high temperatures.

From the liquefaction point, the number of detected degradants increases. The detection of compounds of higher $\mathrm{m} / \mathrm{z}$ signals suggests that polymerization occurs. Among them, compounds, L1 to L3 exhibit $\mathrm{m} / z$ signals of 229, 243 and 257, respectively. Isobaric compounds at $\mathrm{m} / \mathrm{z} 243$ and 257 were detected, suggesting positional isomers.

However, analysis by tandem mass spectrometry was poorly informative because only one fragment at $\mathrm{m} / \mathrm{z} 184$ or 198 was detected for each compound. These data suggest that they are related structures, which may differ from their degree of methylation, as shown by the $14 \mathrm{u}$ difference between the different molecular ions. Possible structures are identified as resulting from linking and cyclization of isocyanic residues on the bethanechol structure (Fig. 12). This decomposition scheme, consisting of cyclic polymerization, would be similar to observations on the thermal decomposition of acetylsalicylic acid. ${ }^{33}$

Moreover, the occurrence of several chemical reactions may explain the complex signals that have been obtained from the DSC experiments. Besides, the identification of the reactants corroborates the autocatalytic property of the reaction first evidenced in the kinetic study.

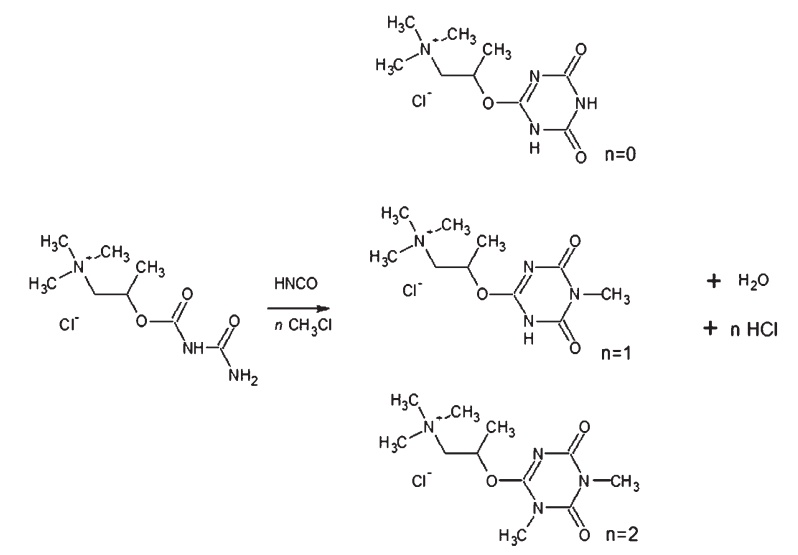

Fig. 12 Structural hypothesis of the degradation impurities L1 to L3.

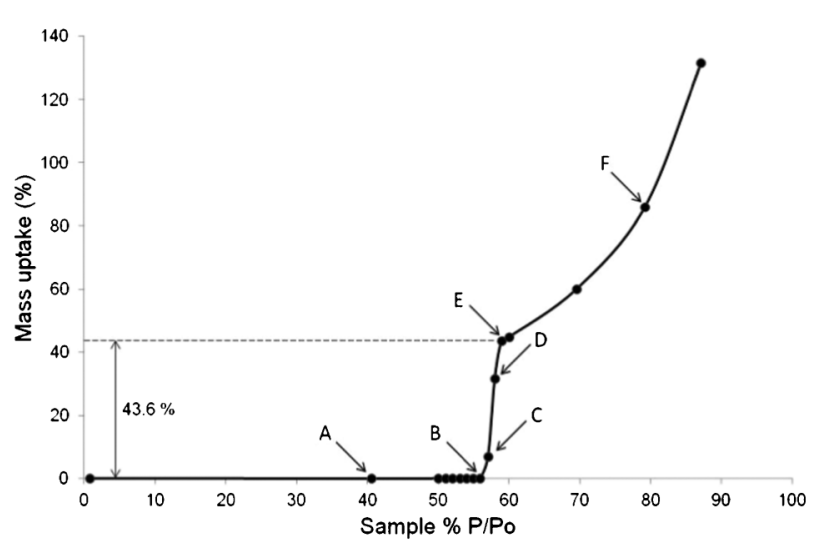

Fig. 13 Bethanechol chloride Dynamic Vapor Sorption isotherm recorded at $25^{\circ} \mathrm{C}$.

\subsection{Stability towards relative humidity}

$\mathrm{BC}$ is described as a hygroscopic material. ${ }^{25}$ This was confirmed by the hygroscopicity test proposed by the European Pharmacopoeia. ${ }^{19}$ This test reveals a weight increase of $\sim 30 \% \mathrm{w} / \mathrm{w}$ under $80 \% \mathrm{RH}$ at $25{ }^{\circ} \mathrm{C}$ after 24 hours. In these conditions, the mass increase allows us to classify $\mathrm{BC}$ as a "very hygroscopic" material. To investigate the BC hygroscopic behavior more precisely, Dynamic Vapor Sorption (DVS) experiments were performed at $25.2{ }^{\circ} \mathrm{C}$. The sorption curve (Fig. 13) associated with images of the sample during the DVS analysis (Fig. 14) shows that BC presents a deliquescent character if $\mathrm{RH}$ is higher than $56 \%$. So far, any BC hydrated phase has been isolated.

Moreover, the data presented in Fig. 13 were exploited to determine with precision the solubility point of $\mathrm{BC}$ in water. ${ }^{34}$ Indeed, as the deliquescence corresponds to a huge absorption of water by the solid, it leads to the formation of a saturated aqueous solution until the complete dissolution of the solid, i.e. the solubility point (point $\mathrm{C}$ to $\mathrm{E}$, Fig. 13). Then, by increasing the $\mathrm{RH}$ parameter, the obtained solution dilutes (point F, Fig. 13). This two-step absorption of water between 56
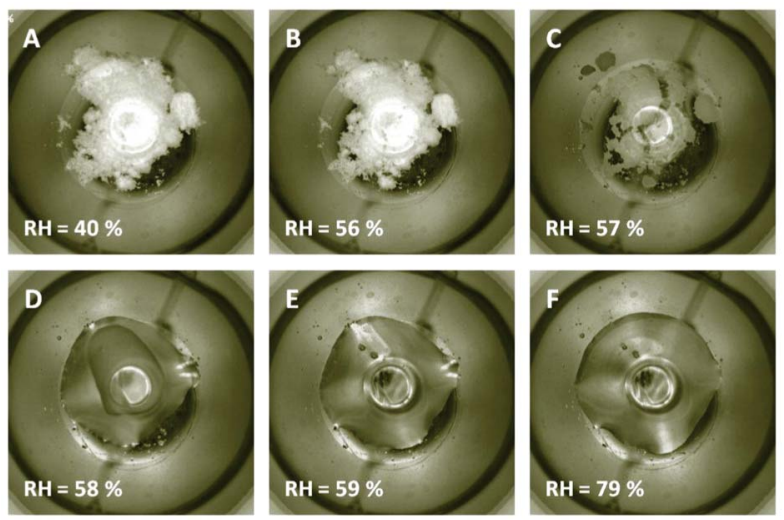

Fig. 14 Images of the BC sample recorded during the Dynamic Vapor Sorption experiment and labeled as in Fig. 13. 
and $90 \% \mathrm{RH}$ is delimited by a disruption in the mass evolution (point E) that corresponds to the BC solubility in water at 25.2 ${ }^{\circ} \mathrm{C}$ calculated at $2.29 \mathrm{~g} \mathrm{~mL}{ }^{1}$. This value is in good agreement with those previously reported in the literature. ${ }^{25}$

\section{Conclusions}

These crystallographic, thermodynamic and kinetic studies allowed us to gain extended knowledge for the use and control strategy of the bethanechol chloride active substance. The water content of the raw material was identified as a key stability attribute, as it affects the mechanical properties (deliquescence above $56 \% \mathrm{RH}$ at $25{ }^{\circ} \mathrm{C}$ ) of the powder and causes chemical degradation. The evidence of the meltingdecomposition reaction implies careful interpretation of the thermal analyses. The advanced thermal degradation pathways determined in this study may not be directly encountered during the life cycle of the drug. Nevertheless, their understanding may provide key tools for the comprehension of the decomposition process of carbamates and ammonium chlorides.

\section{Acknowledgements}

The authors want to thank Jean-Michel Léger for his valuable contribution, Carine Ghaddar and Bernard Do for their support of this work.

\section{Notes and references}

1 G. T. Roling, R. L. Farrell and D. O. Castell, Am. J. Physiol., 1972, 222, 967-972.

2 W. W. Lautt, J. Schafer, M. P. Macedo and D. J. Legare, Can. J. Physiol. Pharmacol., 2011, 89, 135-142.

3 T. Manchana and C. Prasartsakulchai, Int. J. Gynecol. Cancer, 2011, 21, 730-736.

4 A. Varma, J. Smigiel, N. Eck and S. Brooks, Journal of Addiction Medicine, 2011, 5, 227-228.

5 R. K. Khankar and D. J. W. Grant, Thermochim. Acta, 1995, 61-79.

6 C. T. Rhodes and J. T. Carstensen, Drug Stability: Principles and Practices, Marcel Dekker, New York, 3rd edn, 2000.

7 H. G. Brittain, Polymorphism in Pharmaceutical Solids, Informa Healthcare, New York, 2nd edn, 2009.
8 A. Le Bail, Powder Diffr., 2010, 25, 229-234.

9 Rigaku, Rigaku Corporation, Tokyo, Japan, 1996.

10 Rigaku, Rigaku Corporation, Tokyo, Japan, 1998.

11 G. M. Sheldrick, SHELX97, Programs for Crystal Structure Analysis, 1997.

12 G. M. Sheldrick, Acta Crystallogr., Sect. A: Found. Crystallogr., 2008, 64, 112-122.

13 L. J. Farrugia, J. Appl. Crystallogr., 1999, 32, 837-838.

14 L. J. Farrugia, J. Appl. Crystallogr., 2012, 45, 849-854.

15 O. V. Dolomanov, L. J. Bourhis, R. J. Gildea, J. A. K. Howard and H. Puschmann, J. Appl. Crystallogr., 2009, 42, 339-341.

16 M. A. Neumann, J. Appl. Crystallogr., 2003, 36, 356-365.

17 G. S. Pawley, J. Appl. Crystallogr., 1981, 14, 357-361.

18 S. L. Mayo, B. D. Olafson and W. A. Goddard, J. Phys. Chem., 1990, 94, 8897-8909.

19 European Pharmacopoeia Commission and Council of Europe, Technical Guide for the Elaboration of Monographs, 2012.

20 Y. Corvis, P. Négrier, S. Massip, J.-M. Leger and P. Espeau, CrystEngComm, 2012, 14, 7055.

21 M. G. Bursavich and F. R. Fronczech, Acta Crystallogr., Sect. C: Cryst. Struct. Commun., 1997, 53, IUC9700022.

22 A. N. Chekhlov, J. Struct. Chem., 2003, 44, 902-905.

23 B. Jensen, Acta Chem. Scand., Ser. B, 1975, 29, 891-903.

24 Z. Yang and Z. X. Wang, Acta Crystallogr., Sect. E: Struct. Rep. Online, 2009, 65, o1036.

25 M. J. O'Neil, The Merck Index: An Encyclopedia of Chemicals, Drugs, and Biologicals, Merck, Whitehouse Station, NJ, 14th edn, 2006.

26 Pharmaceutical and Medical Devices Agency, Japan, Bethanechol Chloride Monograph. The Japanese Pharmacopoeia, Japanese Ministry of Health, Labour and Welfare, 16th edn, 2011.

27 Y. Corvis, M.-C. Menet, P. Négrier, M. Lazerges and P. Espeau, New J. Chem., 2013, 37, 761-768.

28 P. Adams and F. A. Baron, Chem. Rev., 1965, 65, 567-602.

29 C. E. Bawn, in Chemistry of the Solid State, ed. W. E. Garner, Butterworths Scientific Publications, London, 1955, p. 417.

30 M. E. Brown and B. D. Glass, Int. J. Pharm., 2003, 254, 255-261.

31 R. Rotival, P. Espeau, Y. Corvis, F. Guyon and B. Do, J. Pharm. Sci., 2011, 100, 3223-3232.

32 V. R. Thalladi, A. K. Katz, H. L. Carrell, A. Nangia and G. R. Desiraju, Acta Crystallogr., Sect. C: Cryst. Struct. Commun., 1998, 54(Pt 1), 86-89.

33 G. T. Long, S. Vyazovkin, N. Gamble and C. A. Wight, J. Pharm. Sci., 2002, 91, 800-809.

34 A. Lafontaine, M. Sanselme, Y. Cartigny, P. Cardinael and G. Coquerel, J. Therm. Anal. Calorim., 2013, 112, 8. 